\title{
Uganda records fourth death from Ebola as DRC grapples with epidemic
}

\author{
Henry Wasswa
}

Kampala, Uganda

The Ebola epidemic in the Democratic Republic of Congo (DRC) continues to pose a serious health challenge with the death toll nearing 3000, said the World Health Organization as it called on donors for more support.

Countries neighbouring the DRC are on high alert, strengthening health surveillance systems along their porous borders to stem the risk of Ebola spill-over.

On 30 August, Uganda announced another Ebola infection involving a nine year old girl, a Congolese citizen who had entered the country through the border village of Mpondwe in Kasese district with her mother for treatment. The child had developed symptoms including bleeding from the mouth, high fever, and skin rash. She has since died.

The case is the fourth seen in Uganda since June. The three other victims, all Congolese, were two children and their grandmother, and all died in June.

"The Ministry of Health re-echoes its call to the general public to cooperate with health workers and immigration and security officials to ensure effective screening at all entry points in order to contain the spread of Ebola," said Uganda's deputy health minister Joyce Moriku Kaducu in a statement on 30 August.

Since the outbreak was declared in the DRC last year, Uganda set up a task force to monitor the border, erecting screening points at all entry points and teaching communities ways to avoid contracting the virus.
People have been told to avoid large gatherings involving burials, weddings, and worshipping, and to stop greeting people with hugs and open palms.

WHO says that Ebola has continued to spread in the DRC's provinces of North Kivu, South Kivu, and Ituri "with similar transmission intensity to the previous six weeks," with an average of 77 cases per week. Some 66 health areas in 18 health zones reported new cases, it said.

As of 27 August, there have been 2997 cases of Ebola, with 1998 deaths and 893 survivors, said WHO.

In July, WHO declared the DRC Ebola epidemic an international health emergency shortly after a patient died in the city of Goma, near the border with Rwanda.

The epidemic is the world's second worst on record after an outbreak in west Africa from 2013 to 2016 that killed over 11 000 people out of over 28000 reported cases. DRC's Ebola epidemic is compounded by the country's civil conflict which has displaced over 4 million people and disrupted health activities.

Over 200000 people have been vaccinated against Ebola in the DRC, along with health and frontline workers in Uganda, South Sudan, Rwanda, and Burundi, WHO says

"WHO calls for the full force of all partners to respond and increase their presence in the field to stop Ebola and to tackle one of the largest and most complex humanitarian crises in the world," the agency said. 